Dicle University Journal of Engineering (DUJE)

web: http://dergipark.gov.tr/dumf

Araştırma Makalesi / Research Article

\title{
Meme Kanseri Tümörlerinin Radar Tabanlı Mikrodalga Tekniği ile Görüntülenmesinde Bant Genişliğinin Çözünürlüğe Etkisinin İncelenmesi
}

\section{Investigation of the Effect of Bandwidth on the Resolution of Breast Cancer Tumors Image in Radar-Based Microwave Technique}

\section{Hüseyin Özmen ${ }^{1 *}$, M. Bahaddin Kurt²}

${ }^{1}$ Dicle Üniversitesi, Elektrik Elektronik Mühendisliği Bölümü, Diyarbakır, huseyin.ozmen@ dicle.edu.tr

${ }^{2}$ Dicle Üniversitesi, Elektrik Elektronik Mühendisliği Bölümü, Diyarbakır, bkurt@ dicle.edu.tr

\begin{tabular}{l} 
MAKALE BİLGİLERİ \\
\hline Makale geçmişi: \\
Geliş: 10 Şubat 2020 \\
Düzeltme: 25 Şubat 2020 \\
Kabul: 25 Şubat 2020 \\
\hline Anahtar kelimeler:
\end{tabular}

Mikrodalga görüntüleme, meme kanseri, radar, bant genişliği

\begin{abstract}
ÖZET
Meme kanseri tümörlerinin erken evrede görüntülenmesinde kullanılan mevcut görüntüleme tekniklerinin bazı dezavantajları, radar tabanlı mikrodalga görüntüleme yönteminin güçlü bir alternatif olarak doğmasını sağlamıştır. Bu yöntemde, verici antenden gönderilen Gauss darbe sinyali memeye nüfuz etmekte ve geri saçılan sinyaller alıcı anten tarafindan kaydedilmektedir. Kaydedilen bu sinyaller, çeşitli sinyal işleme aşamalarından geçirildikten sonra görüntüye dönüştürülmektedir. Görüntünün çözünürlüğünü belirleyen en önemli faktörlerden biri de antenin bant genişliğidir. Bant genişliği, verici anten tarafından gönderilen Gauss darbe sinyalinin süresini belirlemektedir. Bant genişliği arttıkça Gauss darbe sinyali kısalmakta, bant genişliği azaldıkça darbe sinyali uzamaktadır. Bu çalışmada $3-11 \mathrm{GHz}$ arasında farklı bant genişliği kombinasyonlarının tümör görüntüsünün çözünürlüğü üzerindeki etkileri arastırılmıstır. 3-5 GHz, 5-7 GHz, 7-9 GHz, 9-11 GHz, 3-7 GHz, 7-11 GHz ve 3-11 GHz frekans aralığında farklı Gauss darbe sinyalleri ile görüntüleme işlemi gerçekleştirilmiştir. Araştırmanın sonunda, en yüksek görüntü çözünürlüğünün, en yüksek bant aralığı olan 3-11 $\mathrm{GHz}$ aralığında elde edildiği görülmüștür.
\end{abstract}

\begin{tabular}{ll}
\hline ARTICLE INFO & \begin{tabular}{l} 
ABSTRACT \\
\cline { 2 - 3 } Article history:
\end{tabular} \\
$\begin{array}{l}\text { Some disadvantages of existing imaging techniques used in the early stage imaging of breast cancer tumors have } \\
\text { led to the emergence of the radar-based microwave imaging method as a powerful alternative. In this method, } \\
\text { the Gaussian pulse signal sent from the transmitting antenna penetrates the breast and the backscattered signals } \\
\text { Reve recorded by the receiving antenna. These recorded signals are converted into images after passing through } \\
\text { Accepted: } 25 \text { February } 2020\end{array}$ & $\begin{array}{l}\text { various signal processing stages. One of the most important factors that determine the resolution of the image is } \\
\text { the bandwidth of the antenna. The bandwidth determines the duration of the Gauss pulse signal sent by the } \\
\text { transmitting antenna. The pulse signal gets shorter as the bandwidth increases, and the pulse signal gets longer as } \\
\text { the bandwidth decreases. In this study, the effects of different bandwidth combinations between 3-11 GHz on the } \\
\text { resolution of the tumor image were investigated. Imaging was performed with different Gauss pulse signals in } \\
\text { the frequency range of 3-5 GHz, 5-7 GHz, 7-9 GHz, 9-11 GHz, 3-7 GHz, 7-11 GHz and 3-11 GHz. At the end of } \\
\text { the study, it was seen that the highest image resolution was obtained in the range of 3-11 GHz, which is the } \\
\text { highest bandwidth range. }\end{array}$ \\
$\begin{array}{l}\text { Microwave imaging, breast } \\
\text { cancer, radar, bandwidth }\end{array}$ &
\end{tabular}

* Sorumlu yazar / Correspondence

Hüseyin ÖZMEN

$\bowtie$ huseyin.ozmen@dicle.edu.tr 


\section{Giriş}

Dünyada meme kanseri kadınlar arasında kanser türleri arasında en ölümcül olan türdür. Hayatta kalma oranı hastalığın erken evrede tespiti ile yükselmektedir [1]. Günümüzde meme kanserinin tespiti için en çok kullanılan yöntem $\mathrm{X}$-ray mamografidir. $\mathrm{Bu}$ yöntem tümörlerin görüntülenmesi için iyonize edici 1şınlar kullanmaktadır ve bu durum yeni kanserler oluşturma riskine sahiptir. Ayrıca memeye uygulanan baskı ağrıya sebep olmaktadır [2].

Son yıllarda araştırmacılar, meme kanserinin erken evrede tespiti için zararsız, ucuz ve konforlu bir yöntem olan mikrodalga görüntüleme tekniği üzerine çalışmalar yapmışlardır. Yapılan araştırmalarda mikrodalga frekanslarında tümörlü dokunun dielektrik sabitinin sağlıklı yağ dokusununkinden daha büyük olduğu görülmüştür [3], [4]. $\mathrm{Bu}$ sayede memeye mikrodalga frekanslarında bir sinyal gönderildiğinde, farklı olarak tümörden bir sinyal geri saçılmaktadır. Tümörden saçılan bu sinyal gerekli teknikler uygulanarak görüntüye dönüştürülmektedir.

Mikrodalga görüntüleme tekniği kendi içinde ikiye ayrılmaktadır. Bunlar; aktif ve pasif yöntemlerdir. Aktif yöntemlerden biri radar tabanlı görüntüleme tekniğidir. 2002 yılında FCC'nin [5] $3.1-10.6 \mathrm{GHz}$ frekans bandının lisanssız kullanımına izin vermesiyle çok geniş bantlı anten tasarımı ve radar tabanlı mikrodalga görüntüleme tekniği ile ilgili çalışmalarda büyük artış olmuştur. Radar tabanlı görüntüleme tekniğinde anten tarafından memeye uyartım sinyali olarak Gauss darbe sinyali gönderilmektedir. Gauss darbe sinyalinin süresi antenin bant genişliğine göre değişmektedir. Literatürdeki çalışmalara göre anten bant genişliğinin artması darbe sinyalinin kısalmasını sağlamakta bu da görüntü çözünürlüğünü arttırmaktadir [6].

$\mathrm{Bu}$ çalışmada, radar tabanlı mikrodalga görüntüleme tekniğinde anten bant genişliğinin ve alt çalışma frekansının meme kanseri tümörü görüntülerinin çözünürlüğünü nasıl etkilediği detaylı bir şekilde sunulmuştur. Mikrodalga görüntüleme sistemi CST Microwave Studio programı kullanılarak simülasyon ortamında oluşturulmuştur. Meme, yarım küre şeklinde tasarlanmış ve içerisine farklı noktalarda $1 \mathrm{~mm}$ yarıçaplı küresel üç adet tümör konumlandırılmıştır. Meme dokularının elektriksel özelliklerinin belirlenmesi için tek kutuplu Debye modeli kullanılmıştır. Meme etrafinda dairesel olarak 12 ayrı noktada zaman domeninde mono-statik ölçümler gerçekleştirilmiştir. Verici anten tarafindan memeye Gauss darbe sinyali gönderilmiş ve geri saçılan sinyal aynı anten tarafından alınmıştır. Kaydedilen sinyaller filtrelendikten sonra geciktir ve topla (Delay-and-Sum) algoritmas1 kullanılarak iki boyutlu görüntüler oluşturulmuştur. Gauss darbe sinyali süresinin görüntü çözünürlüğüne etkisinin ortaya çıkarılması için tümörlü meme, anten çalışma aralığ $13-5 \mathrm{GHz}, 5-7 \mathrm{GHz}, 7-9 \mathrm{GHz}, 9-11 \mathrm{GHz}$, 3-7 $\mathrm{GHz}, 7-11 \mathrm{GHz}$ ve 3-11 $\mathrm{GHz}$ olmak üzere yedi farklı Gauss darbe sinyali ile aydınlatılmıştır. Her durum için görüntüler ve tümör yanıtları $(\mathrm{dB})$ elde edilerek karşılaştırılmıştır.

\section{Radar Tabanlı Mikrodalga Görüntüleme}

Radar tabanlı görüntüleme sisteminde uyartım sinyali verici anten tarafından hedef nesneye gönderilmekte ve geri saçılan sinyal de alıcı anten tarafindan alınmaktadır. Radarların görüntüleme ve nesne tespiti için kullanımında mono-statik, bi-statik ve multi-statik olmak üzere üç farklı konfigürasyon tipi mevcuttur. Meme kanserinin tespitinde bu üç yöntem de araştırmacılar tarafından kullanılmaktadır.

Mono-statik konfigürasyonda bir anten kullanılmaktadır. $\mathrm{Bu}$ anten hem verici hem de alıcı konumundadır. Uyartım sinyali antenden ortama gönderildikten sonra, geri saçılan sinyaller aynı anten tarafindan kaydedilmektedir. Görüntü oluşturulabilmesi için meme etrafında farklı noktalardan ölçümler yapılması gerekmektedir [7], [8].

Bi-statik konfigürasyonda iki tane anten kullanılmaktadır. Antenlerden biri verici konumundayken diğer anten geri saçılan sinyalleri kaydetmektedir. $\mathrm{Bu}$ yöntemde de görüntü oluşturulabilmesi için anten çifti ile 
hedef nesne etrafinda farklı noktalardan ölçümler alınmaktadır [9].

Multi-statik radar konfigürasyonunda ise birçok antenden oluşan anten dizisi meme etrafında dizilmektedir. $\mathrm{Bu}$ yöntemde antenlerden birisi verici iken kalan diğer antenler alıcı olarak çalışmaktadır. Sırayla bütün antenler verici ve kalan antenler alıcı olarak çalıştırıldıktan sonra kaydedilen sinyaller görüntüye dönüştürülmektedir [10].

Bu çalışmada mono-statik radar konfigürasyonu kullanılmıştır. Görüntüleme sistemi CST Microwave Studio simülasyon programında oluşturulmuştur. Meme, $50 \mathrm{~mm}$ yarı çaplı yarım küre şeklinde tasarlanmıştır. Deri tabakasının kalınlığ1 2 mm'dir ve altında tamamen yağ dokusu bulunmaktadır. $\mathrm{Bu}$ çalışmada fibroglandular doku içermeyen düşük yoğunluklu, basit bir homojen meme modeli kullanılmıştır ve bu durum tümörün tespitini kolaylaştırmaktadır. Yağ dokusunun içinde farklı noktalara $1 \mathrm{~mm}$ yarı çaplı küresel üç adet tümör yerleştirilmiştir. Birinci tümör $(\mathrm{x}=-18.59$; $\mathrm{y}=10.9 ; \mathrm{z}=18)$, ikinci tümör $(\mathrm{x}=18.22 ; \mathrm{y}=10.4$; $\mathrm{z}=18)$ ve üçüncü tümör $(\mathrm{x}=-0.2 ; \mathrm{y}=-21 ; \mathrm{z}=18)$ noktalarına konumlandırılmıştır.

Sabit duran memenin etrafinda dairesel olarak 12 farklı noktadan mono-statik ölçümler gerçekleştirilmiştir. Görüntüleme sisteminin konfigürasyonu Şekil 1'de iki boyutlu olarak gösterilmiştir:

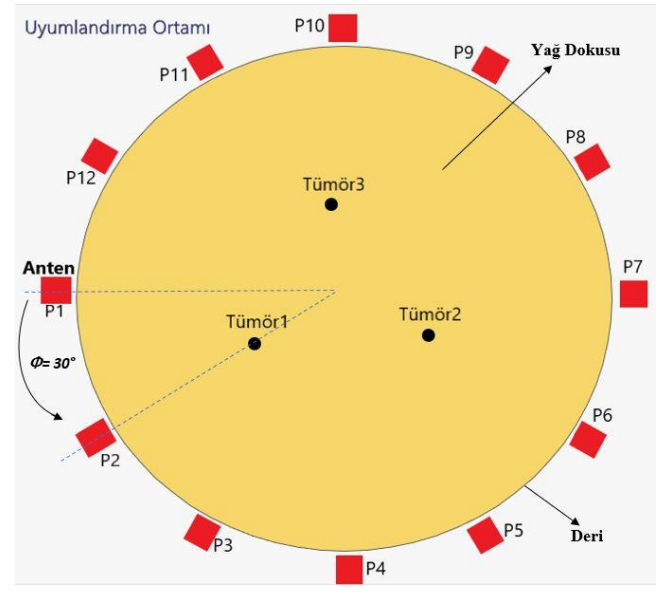

Şekil 1. Mono-statik Mikrodalga Görüntüleme sistemi
Alınan sinyallerdeki gürültüyü azaltmak için antenle meme arasındaki ortamın dielektrik özelliği yăg dokusununki ile aynı yapılarak bir uyumlandırma ortamı oluşturulmuştur. Şekil 1 'de de görüldüğü üzere simülasyon ortamında tasarlanan meme modeli deri, yağ ve tümörden oluşmaktadır. Mikrodalga frekansları altında bu doku tiplerinin dielektrik özellikleri frekansa bağlı olarak değişmektedir. Frekansa bağlı olarak dokuların elekriksel özelliklerini belirlemek için birçok çalışma gerçekleştirilmiştir [3], [4], [11], [12], [13]. Simülasyon ortamında meme dokularının dinamik dielektrik sabitini gerçeğe yakın şekilde elde edebilmek için tek kutuplu Debye modeli [14] kullanılmıştır. Tek kutuplu Debye modeli matematiksel olarak aşağıdaki denklem ile ifade edilmektedir:

$$
\varepsilon_{r}(\omega)=\varepsilon_{\infty}+\frac{\sigma_{s}}{j \omega \varepsilon_{0}}+\frac{\varepsilon_{S}-\varepsilon_{\infty}}{1+j \omega t_{0}}
$$

Denklem (1)'deki parametreler Tablo 1'deki gibi seçildiğinde deri [15], yağ [16] ve tümör'ün [17] frekansa göre dielektrik sabitleri elde edilmektedir.

Tablo 1. Tek Kutup Debye Parametreleri

\begin{tabular}{c|c|c|c|c}
\hline Doku & $\varepsilon_{\infty}$ & $\varepsilon_{s}-\varepsilon_{\infty}$ & $\sigma$ & $\mathrm{t}_{0}$ \\
\hline Deri & 15.63 & 8.2 & 0.82 & 12.6 \\
\hline Yağ & 3.12 & 1.59 & 0.050 & 13 \\
\hline Tümör & 7 & 47 & 0.15 & 7 \\
\hline
\end{tabular}

Tablo 1'e göre elde edilen bağ1l dielektrik sabitlerinin frekansa göre değişimi Şekil 2'de gösterilmiştir.

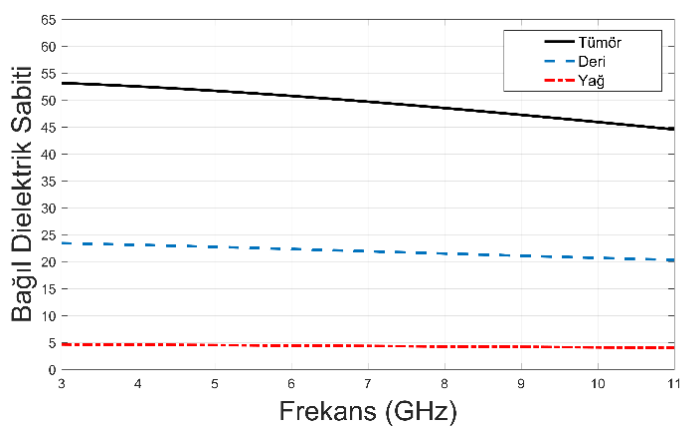

Şekil 2. Memedeki doku tiplerinin 3-11 GHz frekans aralığındaki bă̆ll dielektrik sabitleri

Şekil 2'de de görüldüğü gibi sağlıklı yağ dokusunun dielektrik sabiti ile tümörünki 
arasında büyük bir fark vardır. Aradaki dielektrik sabiti farkı, uyartım sinyali memeye nüfuz ettiğinde tümörün sağlıklı dokuya göre daha yüksek saçılım yapmasına neden olmaktadır. Bu saçılım, radar tabanlı mikrodalga görüntüleme tekniği ile tümörün konumunun tespitini sağlamaktadır.

Meme içerisindeki tümörlerin görüntülenmesi için, alıcı antenlerde toplanan sinyallere bir takım sinyal işleme tekniklerinin uygulanması gerekmektedir. Bunlar; filtreleme, integrasyon ve odaklama aşamalarıdır.

Filtreleme: Alıcı antenlerde kaydedilen sinyaller, ortamdaki tüm dokulardan ve diğer saçıcılardan saçılan sinyallerin toplamıdır. En baskın kısım ise deriden geri saçılan sinyaldir ve genliği tümörden saçılan sinyale göre oldukça yüksektir. $\mathrm{Bu}$ baskın kısımların belirlenip filtrelenmesi için referans olarak boyut, şekil ve doku tipleri bakımından kanserli memeyle aynı olan sağlıklı bir meme modeli kullanılmıştır. $\mathrm{Bu}$ model monostatik olarak bir kez uyartılmış ve geri saçılan sinyal kaydedilmiştir. Daha sonra 12 kanaldaki her sinyalden sırayla çıkarılmıştır. Böylece deri ve yağdan saçılan sinyaller elenerek sadece tümörden saçılan sinyal elde edilmiştir. Referans olarak kullanılan sağlıklı meme modeli, tümörler haricinde kanserli meme modeli ile aynı seçilmezse bu yöntem kullanılarak tatmin edici sonuçlar elde edilmesi güçleşecektir. Oluşacak yeni saçılımlar tümör yanıtı üzerinde gürültüye sebep olacaktır. $\mathrm{Bu}$ yöntem aşağıdaki gibi ifade edilir:

$$
S_{i}^{T Y}=S_{i}^{T}-S^{H}
$$

Denklem (2)'de $S_{i}^{T}$ her kanaldaki sinyali, $S^{H}$ tümörsüz memeden saçılan sinyali, $S_{i}^{T Y}$ ise filtreleme sonucu elde edilmiş tümör yanıtı sinyalini ifade etmektedir.

İntegrasyon: Bir Gauss sinyali olan tümör yanıtından düzgün bir görüntü elde edilebilmesi için sinyalin zarfının alınması gerekmektedir. Hilbert dönüşümü ile bu işlem gerçekleştirilebilmektedir [18] ve aşağıdaki gibi ifade edilmektedir.

$$
\begin{gathered}
H\{s(t)\}=\frac{1}{\pi} \int_{-\infty}^{+\infty} \frac{s(\tau)}{s(t-\tau)} d \tau \\
s_{A}(t)=s(t)+j H\{s(t)\} \\
s_{A}(t)=A(t) e^{j \omega(t)}
\end{gathered}
$$

Hilbert dönüşümü, gerçek değerli bir sinyali, kompleks bileşene sahip analitik bir sinyale dönüştürmektedir. Denklem (4)'te $s(t)$ kalibre edilmiş gerçek değerli sinyali, $s_{A}(t)$ analitik sinyali, $H\{s(t)\}$ analitik sinyalin kompleks bileşenini, Denklem (5)'te ise $A(t)$ sinyalin zarfinı ifade etmektedir.

Odaklama: Görüntü oluşturma işleminin son adımı odaklamadır. İki boyutlu görüntüleme alanı $1 \mathrm{~mm}$ x $1 \mathrm{~mm}$ boyutlarında piksellere bölünmektedir. Her pikselin antene olan uzaklığı ve gecikme zamanları hesaplanmaktadir. Piksellerdeki gecikme zamanına bağlı olarak her pikselin enerji seviyesi hesaplanmaktadır. Enerjinin en yüksek olduğu pikseller tümörün konumunu göstermektedir. $\mathrm{Bu}$ çalıșmada odaklama algoritmas1 olarak geleneksel "Geciktir ve Topla” (Delay-and-Sum) algoritması kullanılmıştır [19]. Bu yöntemin formülasyonu aşağıdaki gibidir:

$$
I(r)=\int_{0}^{T}\left[\sum_{n=1}^{M} S_{n}\left(t-\tau_{n}(r)\right)\right]^{2} d t
$$

Denklem (6)'da; $I(r) r$ uzaklığındaki pikselin enerjisini, $S_{n}$ tümör yanıtını, $\tau_{n}$ her piksel için gecikme zamanını belirtmektedir. Gecikme zamanı aşağıdaki formül ile hesaplanmaktadır.

$$
\tau_{m}\left(r_{0}\right)=\frac{d_{i}}{v . \Delta t}
$$

Denklem (7)'de $d_{i}$ piksel ile anten arasındaki uzaklığı, $\quad v$ dalganın ortamdaki hızını belirtmektedir. $\mathrm{Bu}$ parametreler aşağıdaki formüller ile hesaplanmaktadır:

$$
\begin{gathered}
d_{i}=\frac{\sqrt{\left(x-x_{i}\right)^{2}+\left(y-y_{i}\right)^{2}+\left(z-z_{i}\right)^{2}}}{v} \\
v=\frac{c}{\sqrt{\varepsilon_{r}}}
\end{gathered}
$$

Denklem (9)'da $c$ 1şık hızını, $\varepsilon_{r}$ ortamın bağıl dielektrik sabitini belirtmektedir 


\section{Gauss Darbe Sinyali}

Radar tabanlı mikrodalga görüntüleme yönteminde verici anten uyartım sinyali olarak Gauss darbe sinyali göndermektedir. Gauss darbe sinyalinin süresi bant genişliğine göre değişmektedir. Bant genişliği arttıkça darbe süresi kısalmakta, bant genişliği azaldıkça darbe süresi de artmaktadır. Şekil 3'te 3-10 GHz bant genişsliğinde sinüs modüleli Gauss sinyali görülmektedir.

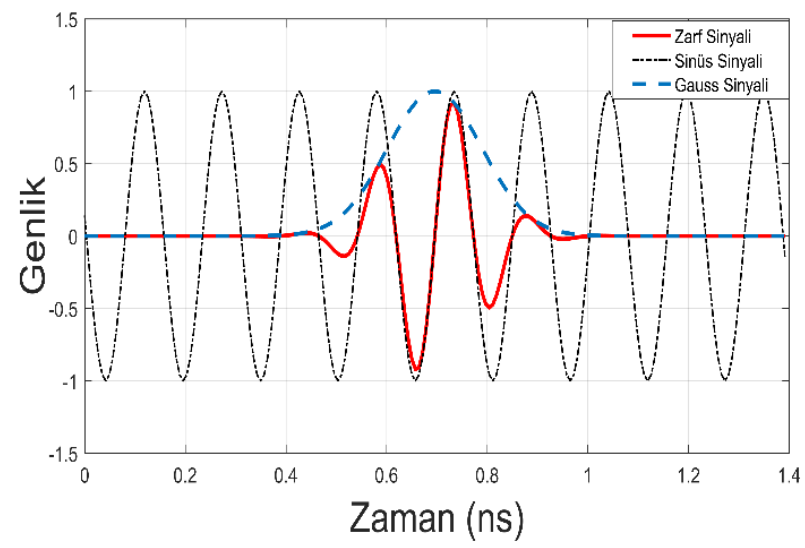

Şekil 3. Gauss darbesi ve bileşenleri

Sinüs modüleli Gauss darbe sinyalinin matematiksel ifadesi aşağıdaki gibidir [20]:

$$
v(t)=v_{0} \sin \left(2 \pi f\left(t-t_{0}\right)\right) e^{\left(\frac{t-t_{0}}{\tau}\right)^{2}}
$$

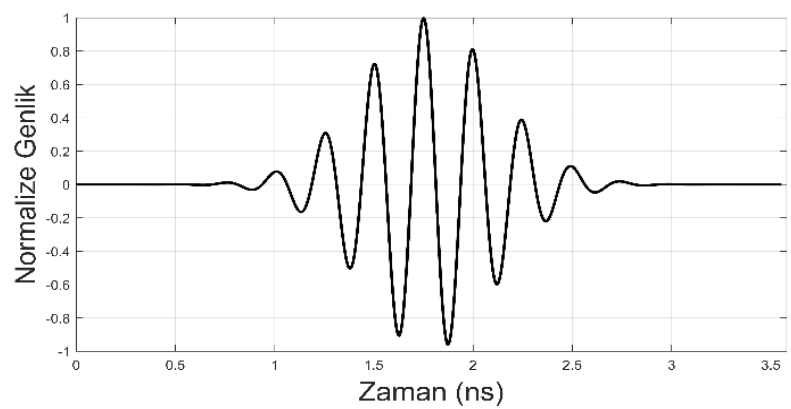

(a)

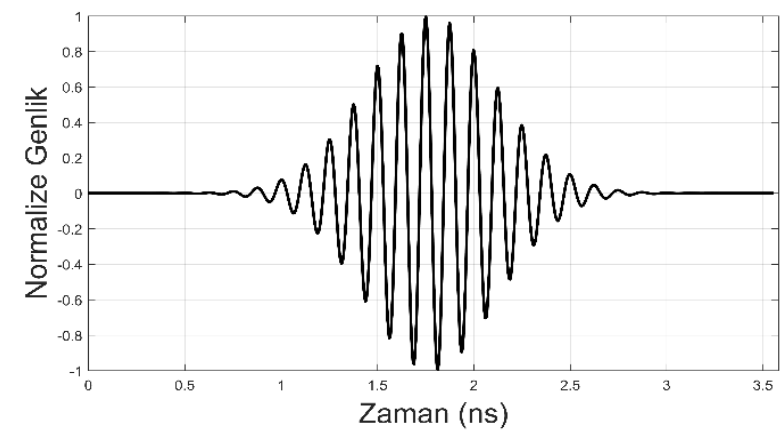

(c)
Denklem (10)'daki ifade iki bileșenden oluşmaktadır. Sinüzoidal kısım ve Gauss sinyali ifade eden eksponansiyel kısımdır. Şekil 4'te bu sinyalin Fourier dönüșümü ve çalıșma aralığ görülmektedir.

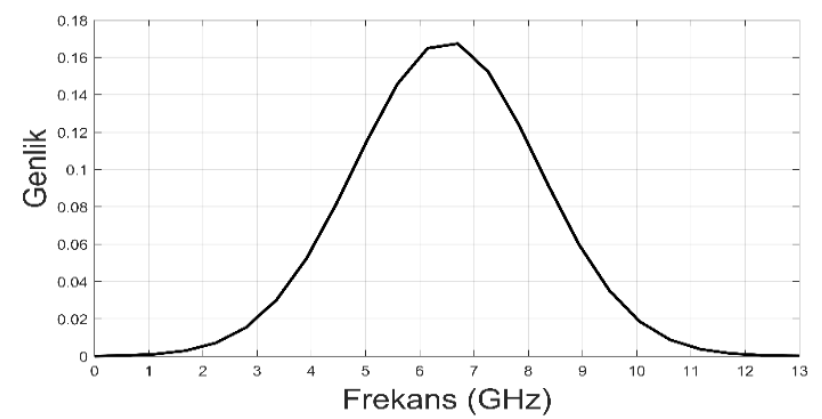

Şekil 4. Gauss darbesinin Fourier dönüşümü

Anten bant genişliği ve merkez frekansının tümör görüntüsü çözünürlügüne etkisinin tespit edilmesi amaciyla $3-11 \mathrm{GHz}$ frekans aralığ içinde $2 \mathrm{GHz}, 4 \mathrm{GHz}$ ve $8 \mathrm{GHz}$ bant genişliğine sahip yedi farklı Gauss darbe sinyali oluşturulmuştur. Şekil 5'te 3-5 GHz (a), 5-7 GHz (b), 7-9 GHz (c) ve 9-11 GHz (d); Şekil 6'da 3-7 GHz (a) ve 7-11 GHz (b); Şekil 7'de 3$11 \mathrm{GHz}$ çalışma frekanslarında oluşturulan Gauss darbe sinyalleri görülmektedir.

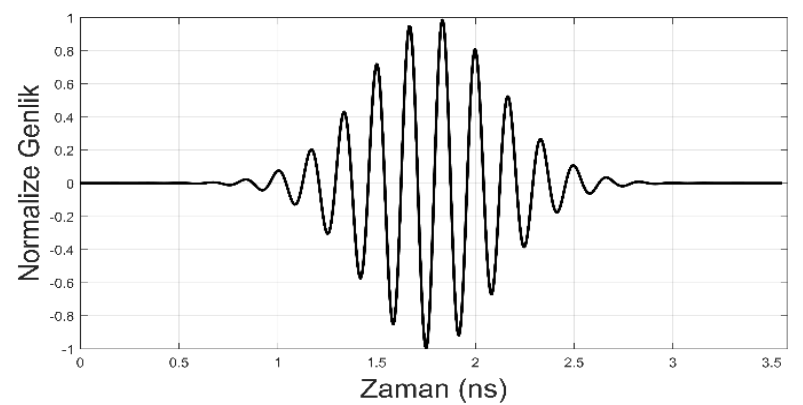

(b)

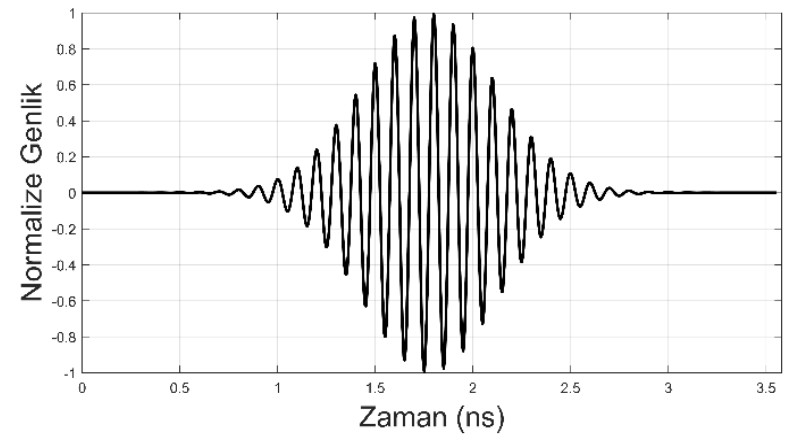

(d)

Şekil 5. $2 \mathrm{GHz}$ frekans bandında Gauss sinyalleri: (a) 3-5GHz, (b) 5-7 GHz, c) 7-9 GHz, d) 9-11 $\mathrm{GHz}$ 


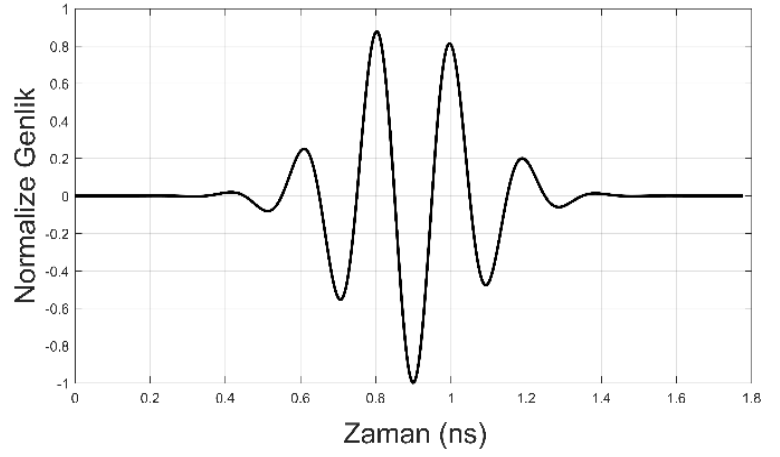

(a)

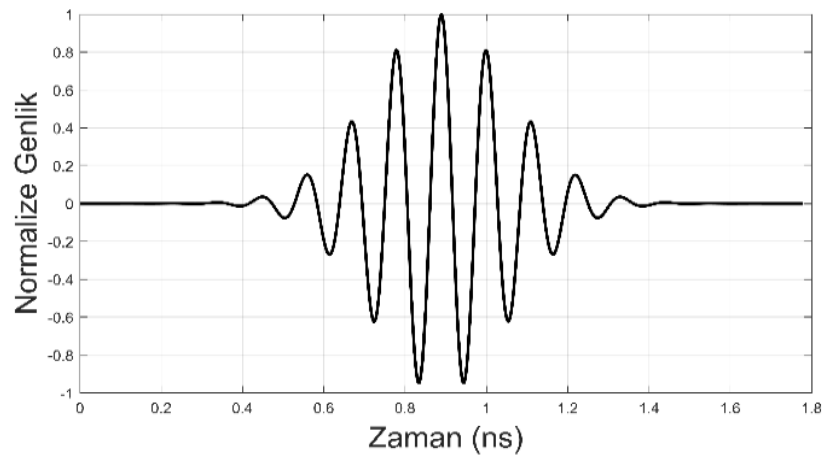

(b)

Şekil 6. $4 \mathrm{GHz}$ frekans bandında Gauss sinyalleri: (a) 3-7 GHz, (b) 7-11 GHz

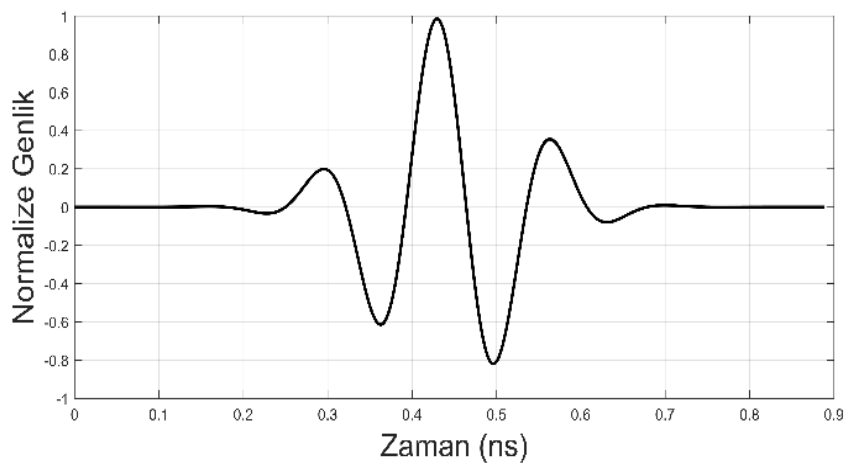

Şekil 7. $8 \mathrm{GHz}$ frekans bandinda Gauss sinyali: 3-11 GHz

Bant genişliğinin $2 \mathrm{GHz}$ olduğu 3-5 GHz, 5-7 $\mathrm{GHz}, 7-9 \mathrm{GHz}$ ve $9-11 \mathrm{GHz}$ frekans bantlarında Gauss darbe sinyalinin süresi yaklaşık $3.5 \mathrm{~ns}$ (Şekil 5); bant genişliğinin $4 \mathrm{GHz}$ olduğu 3-7 $\mathrm{GHz}$ ve $7-11 \mathrm{GHz}$ frekans bantlarında yaklaşık $1.8 \mathrm{~ns}$ (Şekil 6) ve bant genişliğinin $8 \mathrm{GHz}$ olduğu 3-11 GHz frekans aralığında yaklaşık 0.9 ns (Şekil 7) olduğu görülmektedir. Merkez frekans artıkça sinüzoidal bileşenin sıklığı da artmaktadır. Şekil 5 ve Şekil 6 incelendiğinde merkez frekansın sinüzoidal dalganın sıklığına etkisi görülmektedir.

Daha sonra bu sinyaller verici anten tarafindan uyartım sinyali olarak kullanılmış ve farklı çözünürlüklerde yedi adet görüntü elde edilmiştir.

\section{Görüntüleme Sonuçları}

Homojen meme içerisinde konumlanmış $1 \mathrm{~mm}$ yarıçaplı küresel üç tümör filtreleme ve odaklama algoritması kullanılarak görüntülenmiştir. Görüntülemede kullanılacak olan sinyallere ayrıca gürültü eklenmemiştir. Bant genişliğinin çözünürlüğe etkisinin daha iyi anlaşılması için birbirine yakın üç eş tümör kullanılmıștır. Çalıșma sonucunda bant genişliğinin ve merkez frekansın çözünürlük ve tümör yanıtı (dB) üzerindeki etkileri incelenmiştir. Şekil 8'de bant genişliği $2 \mathrm{GHz}$ ve çalıșma aralığı 3-5 GHz (a), 5-7 GHz (b), 5-7 $\mathrm{GHz}$ (c) ve 9-11 GHz olan Gauss darbe sinyali kullanılarak elde edilen görüntüler gösterilmiştir. Şekil 9'da bant genișliği $4 \mathrm{GHz}$, çalışma aralığ 3-7 GHz (a) ve 7-11 GHz (b) olan darbe sinyali kullanılarak görüntüler elde edilmiştir. Şekil 10'daki görüntüde ise bant genişliği $8 \mathrm{GHz}$, çalışma aralığı 3-11 GHz'dir. Görüntüler tümörlerin konumunu $\mathrm{X}-\mathrm{Y}$ düzlemi üzerinde göstermektedir. 


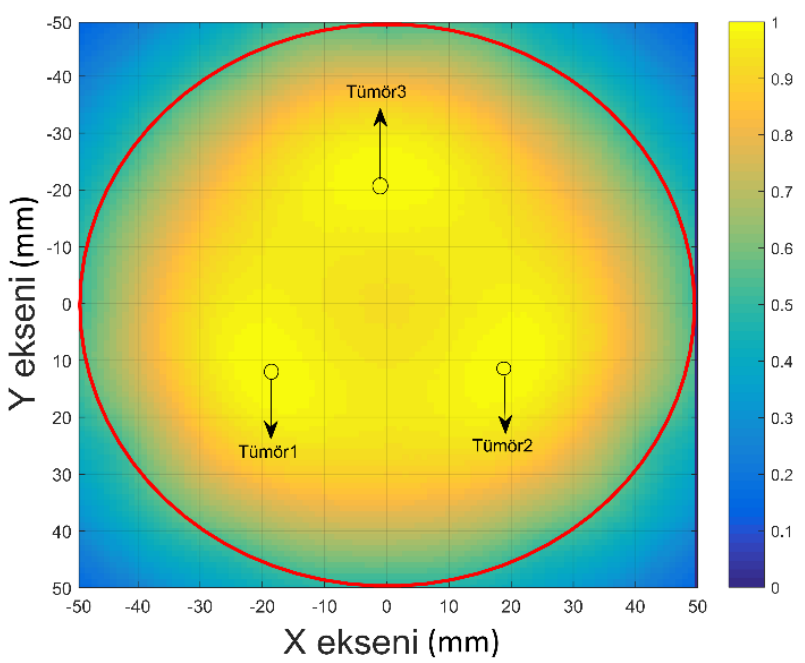

(a)

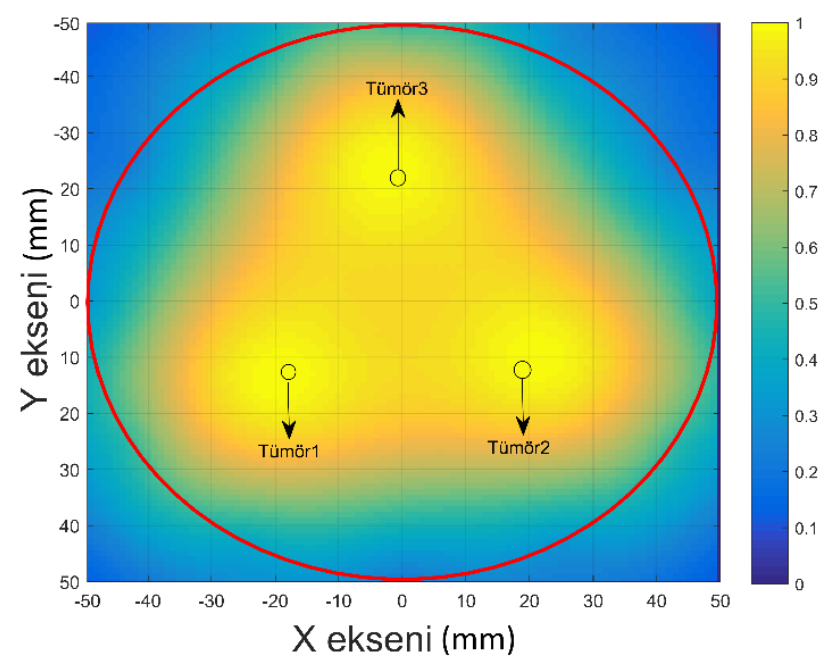

(c)

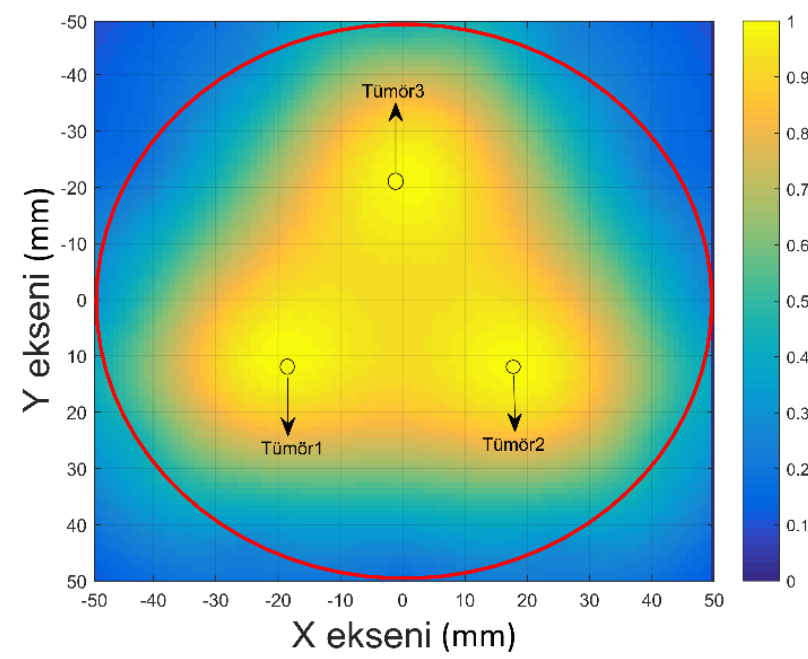

(b)

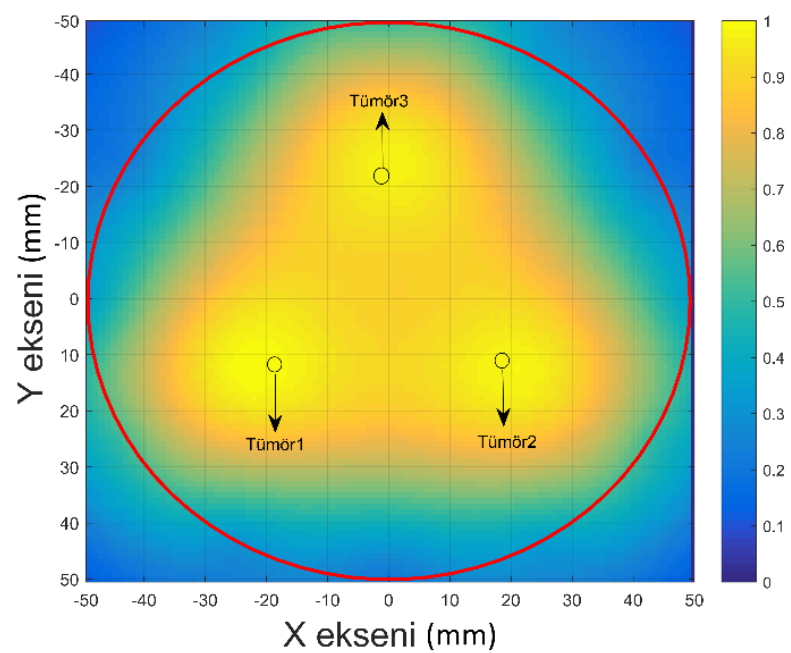

(d)

Şekil 8. Bant genişliği $2 \mathrm{GHz}$ olan Gauss darbe sinyali kullanılarak elde edilen görüntüler: çalışma aralığ (a) 3-5 GHz (b) $5-7 \mathrm{GHz}$, (c) $7-9 \mathrm{GHz}$, (d) $9-11 \mathrm{GHz}$

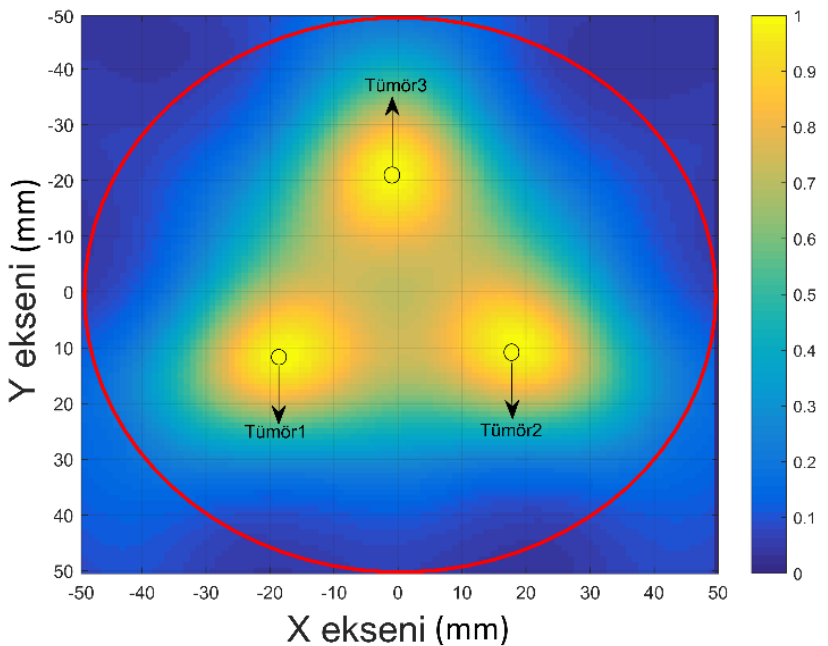

(a)

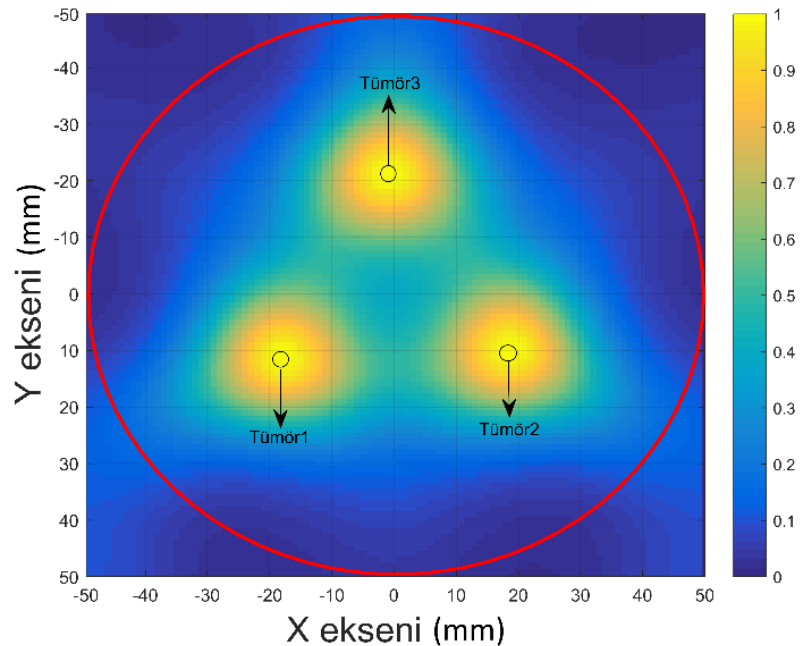

(b)

Şekil 9. Bant genişliği 4 GHz olan Gauss darbe sinyali kullanılarak elde edilen görüntüler: çalışma aralığ (a) 3-7 GHz, (b) 7-11 GHz 


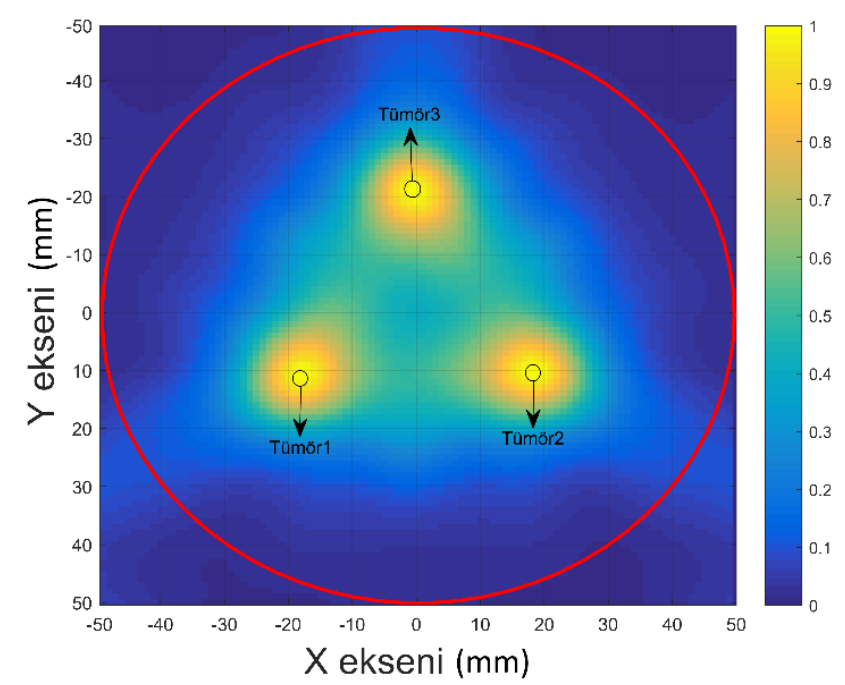

Şekil 10. Bant genişliği $8 \mathrm{GHz}$ olan Gauss darbe sinyali kullanılarak elde edilen görüntü: çalışma aralığ $3-11 \mathrm{GHz}$

Farklı sürelerdeki Gauss darbe sinyalleri uyartım için kullanılmış ve tümör görüntüleri oluşturulmuştur. Yukarıda verilen görüntüleme sonuçları, $\mathrm{z}=18 \mathrm{~mm}$ kesitindeki piksellerin enerjilerinin maksimum enerjiye göre normalize edilmiş değerlerini göstermektedir. Şekil 8, Şekil 9 ve Şekil 10'daki görüntüleme sonuçlarına göre, homojen meme içerisindeki 1 mm yarıçaplı çok küçük üç tümör başarılı bir şekilde görüntülenmiştir. Görüntülerdeki en sarı bölgeler enerjinin en yüksek olduğu tümör konumlarını göstermektedir. Bant genişliği ve merkez frekansa bağlı olarak farklı çözünürlükte görüntüler oluşmuştur. Tümör görüntüleri incelendiğinde, en yüksek bant genişliğine ve dolayısıyla da en kısa Gauss darbe sinyali süresine sahip uyartım sinyali ile elde edilen görüntünün (Şekil 10) en yüksek çözünürlüğe sahip olduğu görülmüştür. Bant genişliği azalıp darbe sinyali süresi uzadıkça elde edilen görüntülerde çözünürlük azalmıştır. Tümör konumunu gösteren sarı renkli bölgeler birbirine karışmıştır. Ayrıca Şekil 9 (b)'de çözünürlüğün Şekil 9 (a)'ya göre daha yüksek olduğu görülmektedir. Aynı durum Şekil 8'de de görülmektedir. Dolayısıyla bant genişliği aynı olan durumlarda merkez frekansındaki artışın çözünürlüğe pozitif etkisinin olduğu tespit edilmiştir.

Bant genişliği ve merkez frekansındaki değişime göre tümör yanıtının nasıl değiştiği $\mathrm{dB}$ cinsinden karşılaştırılmıştır. Tümör yanıtı, özellikle deneysel çalışmalarda büyük önem taşımaktadır. A $\breve{g}$ analizörü cihazının tümörü tespit edebilmesi için tümör yanıtının (dB) cihazın maksimum dinamik aralığından büyük olması gerekmektedir. Tümör yanıtı (dB) aşağıdaki formül ile hesaplanmaktadır [21]:

Tümör Yanıtl $=20 \cdot \log \left(\frac{\left(S_{i}^{T Y}\right)_{p i k-p i k}}{S(t)_{p i k-p i k}}\right)$

Denklemde (11)'de, $S_{i}^{T Y}$ kanallardaki sinyallerin filtrelenmiş formunu ve $S(t)$ ise anten tarafından gönderilen uyartım sinyani ifade etmektedir. Bant genişliği $2 \mathrm{GHz}, 4 \mathrm{GHz}$ ve 8 $\mathrm{GHz}$ olan sinyaller ile elde edilen tümör yanıtları sırasıyla Şekil 11, Şekil 12 ve Şekil 13 'te gösterilmiştir:

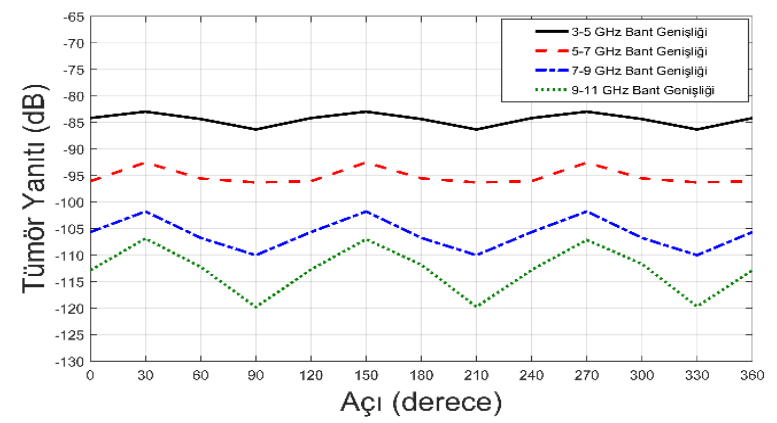

Şekil 11. Bant genişliği $2 \mathrm{GHz}$ olduğunda elde edilen tümör yanıtlart

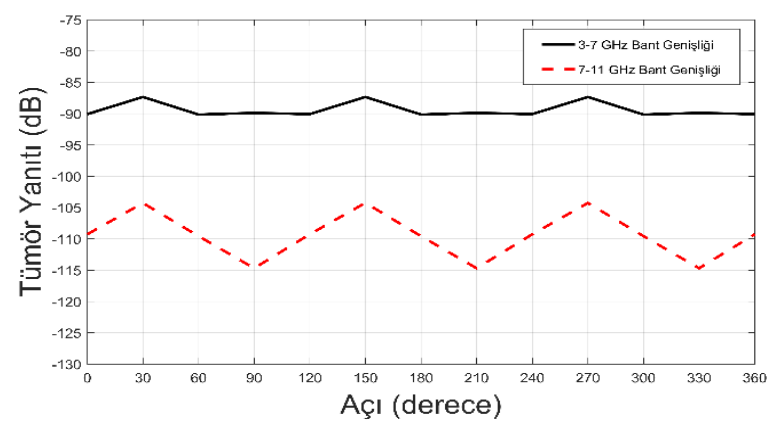

Şekil 12. Bant genişliği $4 \mathrm{GHz}$ olduğunda elde edilen tümör yanıtları

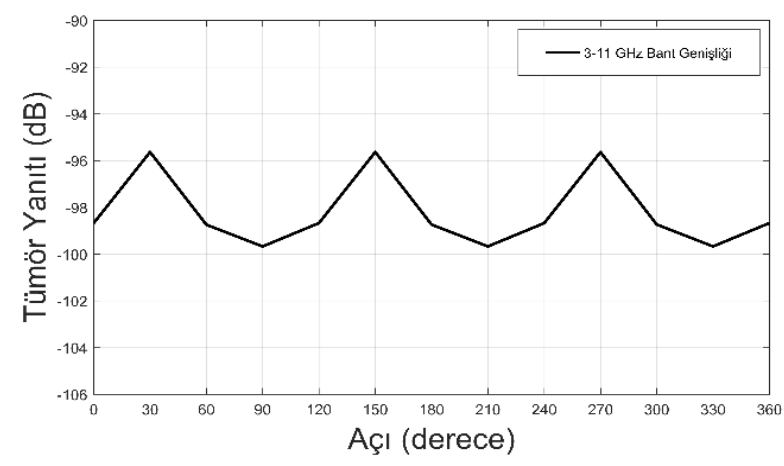

Şekil 13. Bant genişliği $8 \mathrm{GHz}$ olduğunda elde edilen tümör yanıtları 
Şekil 11, Şekil 12 ve Şekil 13'teki sonuçlara göre merkez frekans küçüldükçe tümör yanıtının arttığ görülmektedir. Bu çalışmada modellenen meme dokuları dinamik dielektrik sabitine sahiptirler ve 3-11 GHz frekans aralığında alt frekanslarda daha yüksek dielektriğe sahipken, frekans arttıkça dielektrik sabitleri azalmaktadır. Dolayısıyla tümör yanıtında frekansa bağlı olarak değişimler olabilmektedir.

\section{Sonuç}

$\mathrm{Bu}$ çalışmada, farklı sürelerdeki Gauss darbe sinyalleri uyartım için kullanılmış ve standart görüntüleme algoritmaları kullanılarak basit bir homojen meme modeli içerisindeki $1 \mathrm{~mm}$ yarıçaplı üç tümör görüntülenmiştir. Tümör görüntüleri analiz edildiğinde, en yüksek bant genişliğine ve dolayısıyla da en kısa Gauss darbe sinyali süresine sahip sinyal ile elde edilen görüntülerin en yüksek çözünürlüğe sahip olduğu gözlemlenmiştir. Bant genişliği azalıp darbe sinyali süresi uzadıkça elde edilen görüntülerde çözünürlük azalmıştır. Ayrıca düşük merkez frekanslı sinyaller ile elde edilen tümör yanıtlarının, yüksek merkez frekanslı sinyallerle elde edilenlere göre daha büyük olduğu görülmüştür. Buna neden olan etkenler; 3-11 GHz frekans bandı aralığında meme dokularının elektriksel özelliklerinin frekansa bağlı değişimleri ve yüksek frekanslarda dalga penetrasyonundaki zayıflama olarak düşünülmektedir. Bu konuda kesin bir yargıya ulaşmak için elektriksel özellikleri frekansa bağlı olarak değişmeyen bir meme modeli kullanılarak sonuçlar karşılaştırılabilir.

\section{Teşekkür}

Yazarlar finansal destek için Dicle Üniversitesi Bilimsel Araştırma Projeleri Koordinatörlüğü’ne (Proje Numaras1: MÜHENDİSLİK.19.001) teşekkür ederler.

\section{Kaynaklar}

[1] S. Kwon ve S. Lee, "Recent Advances in Microwave Imaging for Breast Cancer Detection", International Journal of Biomedical Imaging Volume 2016, Article ID 5054912, 25 pages.

[2] A. Berrington de González ve S. Darby, "Risk of cancer from diagnosticX-rays:Estimatesfor the U.K.and 14 othercountries", Lancet, vol. 363, no. 9406, pp. 345-351, Jan. 2004.

[3] S. S. Chaudhary, R. K. Mishra, A. Swarup, ve J. M. Thomas, "Dielectric properties of normal $\&$ malignant human breast tissues at radiowave \& microwave frequencies,", Indian Journal of Biochemistry and Biophysics, vol. 21, no. 1, pp. 76-79, 1984.

[4] A. J. Surowiec, S. S. Stuchly, J. R. Barr, ve A. Swarup, "Dielectric properties of breast carcinoma and the surrounding tissues," International Journal of Biomedical Imaging 21 IEEE Transactions on Biomedical Engineering, vol. 35, no. 4, pp. 257-263, 1988.

[5] New public safety applications and broadband internet access among uses envisioned by FCC authorization of ultra-wideband technology FCC news release (February 14, 2002). Available at (http://ftp.fcc. Gov /Bureaus/ Engineering Technology/ News Releases/2002/ nret0203.pdf)

[6] S.C. Hagness, A. Taflove ve J. Bridges. "TwoDimensional FDTD Analysis of a Pulsed Microwave Confocal System for Breast Cancer Detection: Fixed-Focus and Antenna-Array Sensors", IEEE TRANSACTIONS ON BIOMEDICAL ENGINEERING, VOL. 45, NO. 12, DECEMBER 1998.

[7] X. Li ve S. C. Hagness, "A confocal microwave imaging algorithm for breast cancer detection," IEEE Microwave and Wireless Components Letters, vol. 11, no. 3, pp. 130-132, 2001.

[8] EC Fear, SC Hagness, Meaney, PM Okoniewski, MA Stuchly, "Enhancing breast tumor detection with near-field imaging. IEEE Microwave Magazine 3(1):48-56, 2002.

[9] B. Guo, Y. Wang, J. Li, P. Stoica ve R. Wu, "Microwave Imaging via Adaptive Beamforming Methods for Breast Cancer Detection", Progress In Electromagnetics Research Symposium 2005, Hangzhou, China, August 22-26.

[10] R. Nilavalan, A. Gbedemah, I.J. Craddock, X. $\mathrm{Li}$ ve S. C. Hagness, "Numerical Investigation of Breast Tumour Detectionusing Multi-Static Radar”. Electronics Letters 39(25):1787-1789. 
[11] A. M. Campbell ve D. V. Land, "Dielectric properties of female human breast tissue measured in vitro at $3.2 \mathrm{GHz}$," Physics in Medicine and Biology, vol. 37, no. 1, pp. 193210, 1992.

[12] W. T. Joines, Y. Zhang, C. Li ve R. L. Jirtle, "The measured electrical properties of normal and malignant human tissues from 50 to 900 MHz," Medical Physics, vol. 21, no. 4, pp. 547-550, 1994.

[13] M. Lazebnik, D. Popovic, L. McCartney et al., "A large-scale study of the ultrawideband microwave dielectric properties of normal, benign and malignant breast tissues obtained fromcancer surgeries," Physics in Medicine and Biology, vol. 52, no.20, pp. 6093-6115, 2007.

[14] M. Okoniewski, M. Mrozowski ve M. A. Stuchly, "Simple treatment of multi-term dispersion in fdtd," IEEE Microwave and Guided Wave Letters, Vol. 7, 121-123, 1997.

[15] C. Gabriel, S. Gabriel ve E. Corthout, "The dielectric properties of biological tissues: I. literature survey," Phys. Med. Biol., Vol. 41, No. 11, 2231-2249, Nov. 1996.

[16] E. Zastrow, S. K. Davis, M. Lazebnik, F. Kelcz, B. D. V. Veen ve S. Hagness, "Development of anatomically realistic numerical breast phantoms with accurate dielectric properties for modeling microwave interactions with the human breast," IEEE Transactions on Biomedical Engineering, Vol. 55, No. 12, 2792-2800, Dec. 2008.

[17] E. J. Bond, X. Li, S. C. Hagness ve B. D. V. Veen, "Microwave imaging via space-time beamforming for early detection of breast cancer," IEEE Transactions on Antennas and Propagation, 1690-1705, 2003.

[18] Zhang, "H. Microwave Imaging for UltraWideband Antenna Based Cancer Detection", Ph.D. Thesis, The University of Edinburgh, Edinburgh, UK, 2015.

[19] J. Li, P. Stoica ve Z. Wang, ”On robust Capon beamforming and diagonal loading. IEEE Transactions on Signal Processing 51(7):17021715, 2003.
[20] S.C. Hagness, A. Taflove ve J. Bridges. "Three-Dimensional FDTD Analysis of a Pulsed Microwave Confocal System for Breast Cancer Detection: Design of an Antenna-Array Element". IEEE Transactions On Antennas And Propagation, Vol. 47, No. 5, May 1999.

[21] S. Hagness, A. Taflove ve J. Bridges, "Wideband ultralow reverberation antenna for biological sensing," Electronics Letters, vol. 33, no. 19 , pp. 1594-1595, 1997. 